Conductivity Histories Measured in Shock-Dispersed-Fuel

Explosion Clouds

A. L. Kuhl

April 8, 2010 
This document was prepared as an account of work sponsored by an agency of the United States government. Neither the United States government nor Lawrence Livermore National Security, LLC, nor any of their employees makes any warranty, expressed or implied, or assumes any legal liability or responsibility for the accuracy, completeness, or usefulness of any information, apparatus, product, or process disclosed, or represents that its use would not infringe privately owned rights. Reference herein to any specific commercial product, process, or service by trade name, trademark, manufacturer, or otherwise does not necessarily constitute or imply its endorsement, recommendation, or favoring by the United States government or Lawrence Livermore National Security, LLC. The views and opinions of authors expressed herein do not necessarily state or reflect those of the United States government or Lawrence Livermore National Security, LLC, and shall not be used for advertising or product endorsement purposes.

This work performed under the auspices of the U.S. Department of Energy by Lawrence Livermore National Laboratory under Contract DE-AC52-07NA27344. 


\title{
Conductivity Histories Measured in Shock-Dispersed-Fuel Explosion Clouds
}

\author{
A. L. Kuhl \\ Lawrence Livermore National Laboratory \\ Livermore, California, USA 94551
}

Lawrence Livermore National Laboratory

April 1, 2010

UCRL-xxxxx 


\section{Electro-Magnetic Effects Due to the Detonation of SDF Charges ${ }^{1}$}

\section{Introduction}

The notion of high ion and electron concentrations in the detonation of aluminized explosive mixtures has aroused some interest in electro-magnetic effects that the SDF charges might generate when detonated. Beside the scientific aspects at least two questions appear to be of practical interest:

- Does the detonation of an SDF charge create electro-magnetic disturbances strong enough to affect the operation of electrical infrastructure in for example a tunnel system?

- Does the detonation of an SDF charge in a tunnel system create an electromagnetic signature that relays information of the charge performance to the outside environment?

Motivated by this interest we have started to investigate whether significant electromagnetic effects show up in our small-scale experiments. However, the design of instrumentation for this purpose is far from straightforward, since there are a number of open questions:

- If electro-magnetic effects go along with the detonation of SDF charges, what is the nature of the perturbances? What is their magnitude or - in practical terms what is the sensitivity of a diagnostic tool needed to detect them? What is the frequency range of the perturbances, a question that relates to the bandwidth of the diagnostic tool?

- How do our small-scale set-ups affect electro-magnetic effects? For example, the small-scale models are usually closed chambers, vessels or tunnels manufactured from steel and thus conductive. To the outside they act as a Faraday gage to electro-magnetic waves inside they act as a resonator or wave-guide. A mismatch between the possible electromagnetic eigen-modes of the models and the preferred frequency range of the disturbances will result in strong damping of the effects.

- Is it possible to differ between electro-magnetic effects from the detonating charge and electro-magnetic effects that are generated by the ignition system for our small-scale charges? This ignition system is based on a pulsed high voltage discharge and creates its own electro-magnetic signature for the initial 10 to $20 \mu \mathrm{s}$ after ignition.

Thus the main aim of the feasibility tests is to find - if possible - a simple and reliable method that can be used as a diagnostic tool for electro-magnetic effects.

\footnotetext{
${ }^{1}$ Neuwald, P., Reichenbach, H., and Kuhl, A. L., Laboratory Experiments of ShockDispersed-Fuel Explosions (Chapter 10: Electromagnetic effects due to the detonation of SDF charges) Annual Report 2004, Fraunhofer Instritut Kurzzeitdynamik: Ernst-MachInstitut, Eckersraße 4, 97104 Freiburg, Germany, pp. 79-99, 2004.
} 


\section{Test Chamber and Diagnostics}

Most of the feasibility tests were done in the steel model of a $3 \mathrm{~m}$ long tunnel section of $8 \mathrm{~cm} \times 8 \mathrm{~cm}$ cross-section. This set-up is shown in Figure 1. PETN or SDF charges were detonated $214 \mathrm{~mm}$ from the closed tunnel front.

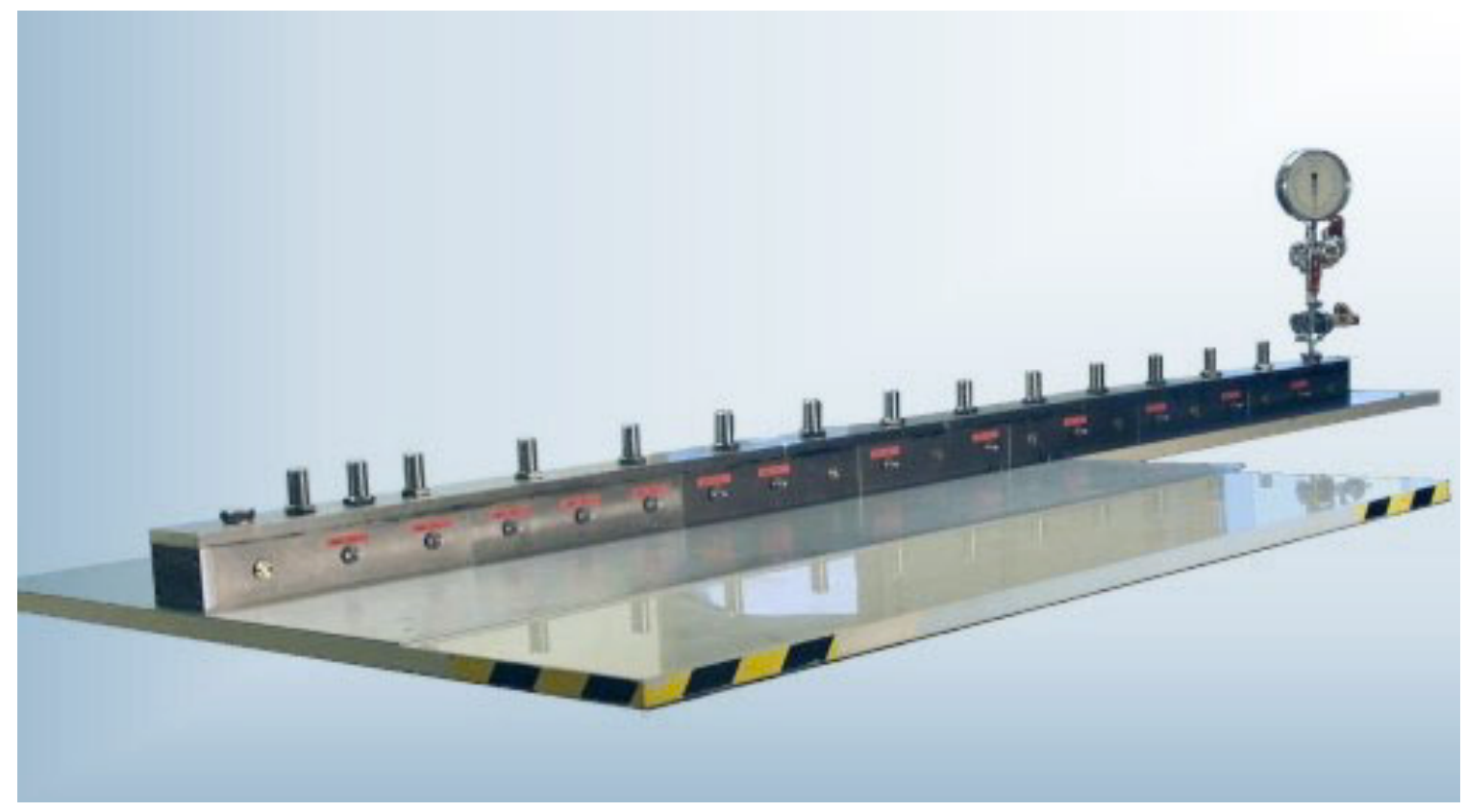

Figure 1. Photograph of the tunnel model. The charges are mounted near to the closed tunnel entrance (left end of the tunnel). The side-wall shows a number of boreholes where piezo-electric gages or the conductivity probe can be installed. The chimney-like elements on the roof can hold photo-diodes.

A number of different possibilities to diagnose electro-magnetic effects were tested in this environment. These included:

- Measurement of the current from the steel model to the ground

- Voltage induced in an antenna-like pick-up

- Voltage induced in single cables, cable pairs and cable loops spanned along the tunnel axis slightly above the tunnel floor

- Voltage induced in a coil around a non-conductive tunnel segment close to the charge location

Most of the test methods showed signals that originate from the high voltage discharge that is used for charge ignition. The energy on the capacitor used in the ignition system is typically $32 \mathrm{~J}$ and thus small to the energy available in the detonation and combustion of the charges. The ignition signals occur during the first 20 to $40 \mu \mathrm{s}$ after the ignition and are typically damped sine waves of around $125 \mathrm{~Hz}$. Further signals were observed in some tests starting at around 80 to $100 \mu$ s after the detonation. These signals were usually weak compared to the ignition signal in most test methods; their occurrence has a low repeatability and their amplitude strongly varied in those cases where they were 
observed. Currently none of the above methods meets the requirements for a diagnostic tool; thus we will not discuss individual results here. The investigation will be continued with more sensitive arrangements.

Besides the methods listed above we also investigated a less direct diagnostic tool based on the measurement of the electro-conductivity in the detonation cloud. This proved to yield more reproducible results and will be discussed in more detail below.

\section{Measurement of the Electro-Conductivity of the Products from SDF Explosions}

Two sensor types were designed for probing the electro-conductivity. In both cases the general design principle is that of a capacitor generating an electrical field, which causes a current, once a conductive material fills the gap between the capacitor electrodes.

The first version utilizes two steel adapters that we normally use to install gages into our models. A sketch of the arrangement is shown in Figure 2. We embedded a brass cylinder into an isolating cylinder of Teflon, which was inserted into a borehole of the steel bolt, that we use as the adapter. The brass cylinder was connected to the inner lead of a BNC connector, while the shielding of the BNC connector was in metallic contact to the steel bolt, which itself, when installed, is in connection with the steel walls of tunnel model. Two bolts were installed into the tunnel walls just opposite from each other. The two electrodes are connected to a battery with a resistor of about $5 \mathrm{k} \Omega$ inserted into the circuit (see Figure 3). The signal that is monitored is the voltage drop at the resistor. If the material between the electrodes is nonconductive, there is no current in the circuit and the voltage drop at the resistor is zero. If we short-circuit the two capacitor electrodes, we will have a current IMAX in the circuit that is limited by the resistor and the voltage drop $U_{2}$ at the resistor is equal to the battery voltage $U_{0}$.

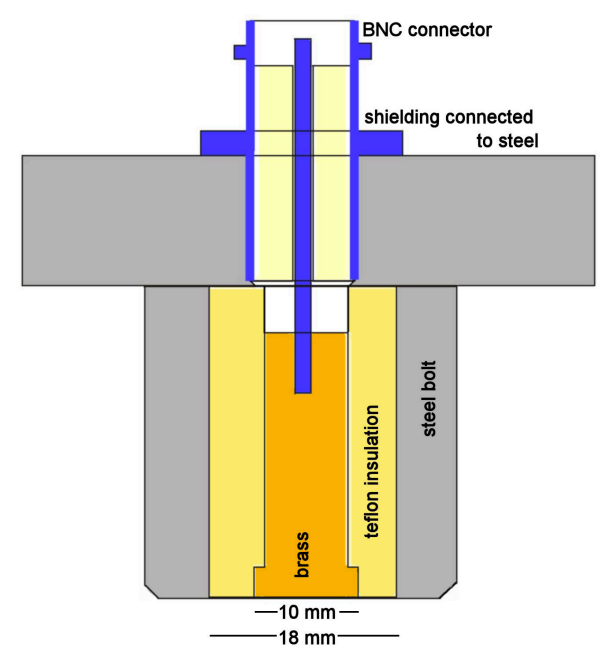

Figure 2. Single electrode used for the first version of a conductivity probe. When mounted into the tunnel wall, the electrode surface is flush with inner tunnel wall. 


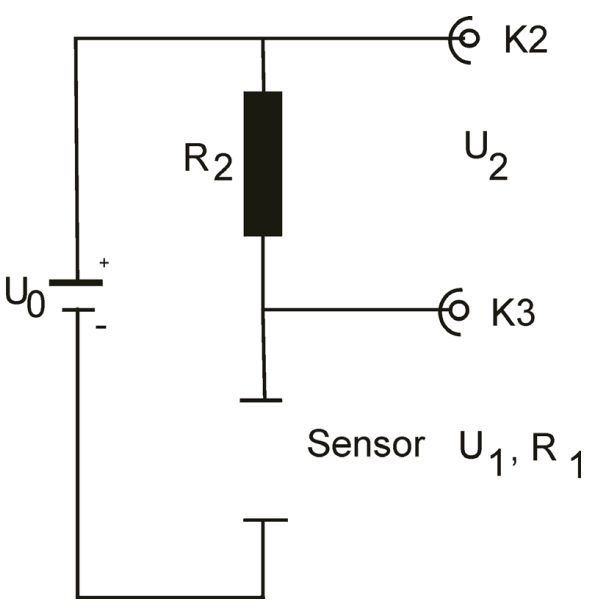

Figure 3. Electric circuit formed by the pair of electrodes, a resistor and a battery as voltage supply.

If the electro-conductivity of the material between the electrodes is finite, the current $I$ through the circuit is smaller than IMAX. The voltage drop at the resistor in this case is:

$$
U_{2}=R_{2} I
$$

The potential difference between the two electrodes is thus:

$$
U_{1}=U_{0}-U_{2}
$$

If we assume for simplicity that the pair of electrodes forms an ideal capacitor, it generates a homogeneous electrical field of the strength

$$
E=U_{1} / d
$$

where $d$ is the distance between the electrodes. If the material in the electrical field has a conductivity $\sigma$, the field gives rise to a current density of

$$
j=\sigma E=\sigma\left(U_{0}-U_{2}\right) / d
$$

The current $I$ must pass through the surface area $S$ of both electrodes. In the idealized arrangement the current will thus be:

$$
I=\sigma\left(U_{0}-U_{2}\right) S / d
$$

The conductivity can be calculated from the measured voltage $U_{2}$ as follows:

$$
\sigma=\frac{U_{2}}{U_{0}-U_{2}} \cdot \frac{1}{R_{2}} \cdot \frac{d}{S}
$$


This is nevertheless only a very crude approximation: our electrodes have a diameter of $10 \mathrm{~mm}$ and are set apart $80 \mathrm{~mm}$, so that the concept of a homogeneous field will not hold. In addition they are installed into the walls of a metallic tube and the metal walls will further deform the electrical field. An impression of the deformed field is shown in Figure 4, which is from a two-dimensional electro-static FEM calculation. Furthermore, the approach outlined above is essentially an electro-static one and neglects the more complex coupling between unsteady electrical fields and currents.

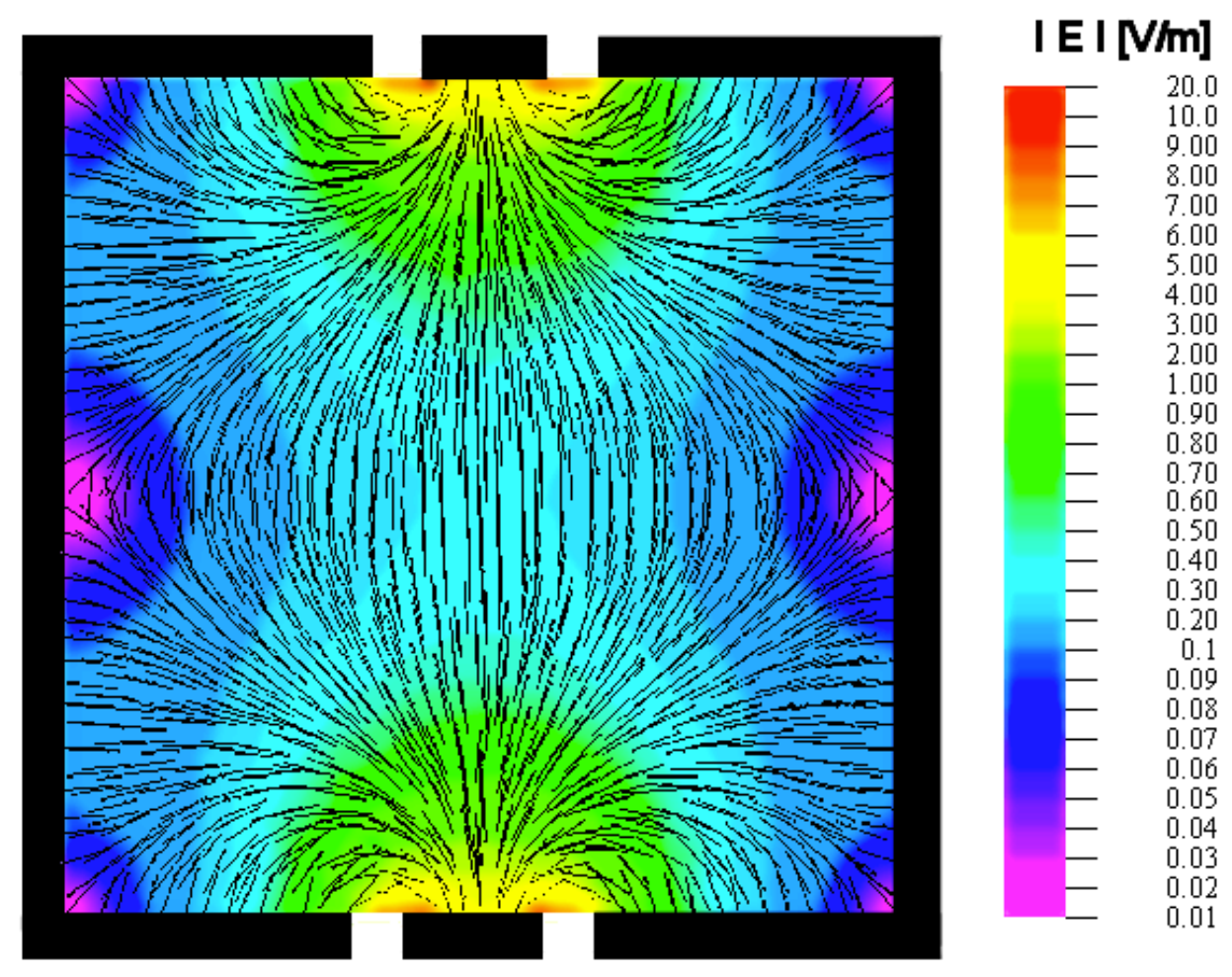

Figure 4. Two-dimensional electro-static FEM simulation of the electrical field in the tunnel. Potential of the tunnel walls $0 \mathrm{~V}$, potentials of the two electrodes $\pm 5 \mathrm{~V}$.

For a couple of initial tests we installed the conductivity probe at $x=356.7 \mathrm{~mm}$, i.e., about $143 \mathrm{~mm}$ downstream from the charge location. We started the experiments with bare spherical PETN charges. The results are shown in Figure 5. The red curve for a charge of $0.56 \mathrm{~g}$ PETN shows a sharp increase of the conductivity at about $0.5 \mathrm{~ms}$. At this instant the primary blast has been reflected at the closed tunnel front and this reflection is arriving or has just arrived at the location of the conductivity sensor. No significant signal is found directly behind the primary shock front, which passes the sensor location at around $120 \mu \mathrm{s}$. For the charges with about $1 \mathrm{~g}$ a signal is found behind the passage of the primary blast front, though it is also strongly enhanced upon the arrival of the front reflected at the closed tunnel entrance. In the case of the 1-g charges this front arrives slightly earlier at the sensor location than in the case of the 0.56 -g charge, because the larger charges create a stronger primary wave. The maximum value of the electroconductivity is around $0.022 \mathrm{~S} / \mathrm{m}$. 


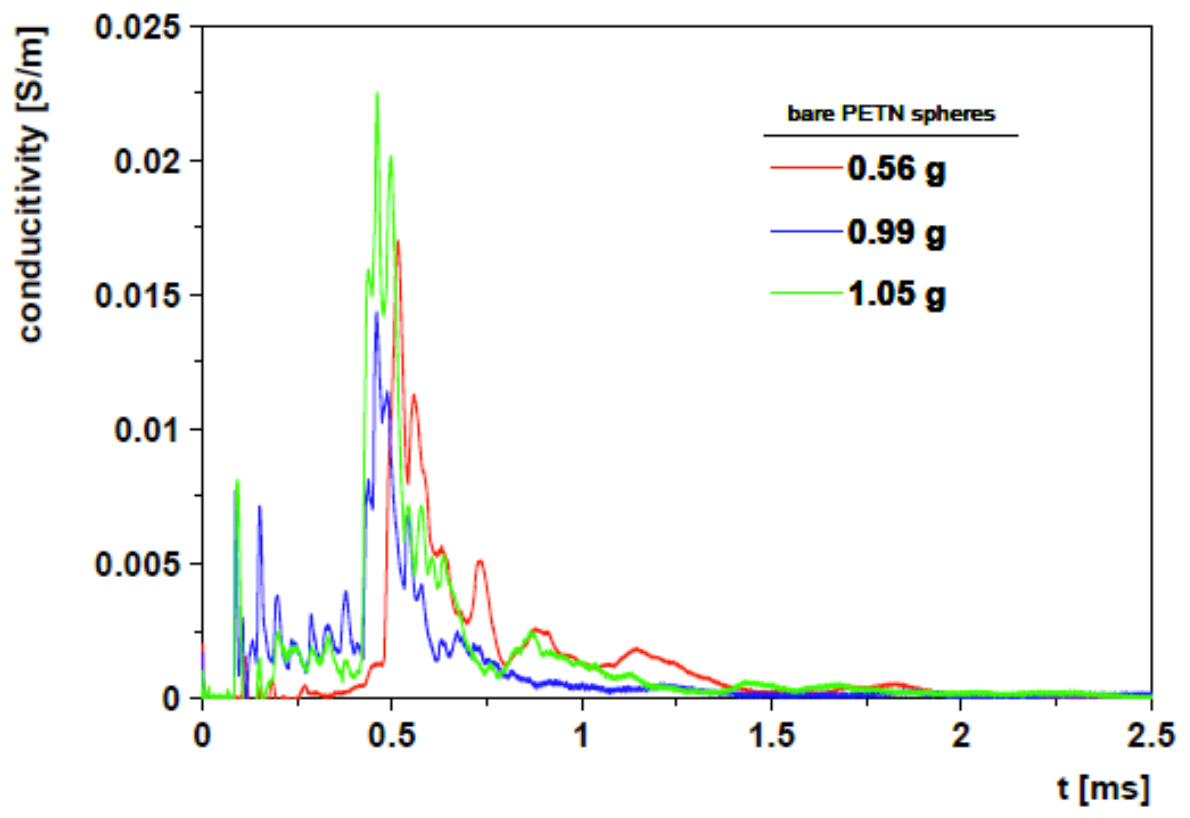

Figure 5. Time history of the electro-conductivity at $x=356.7 \mathrm{~mm}$ in the $3-\mathrm{m}$ tunnel model. Three tests with bare spherical PETN charges of $0.56 \mathrm{~g}, 0.99 \mathrm{~g}$ and $1.05 \mathrm{~g}$. Measured with the wall-mounted sensor.

Figure 6 shows the results from six tests with SDF(Al-flake) charges (standard design, fill $1 \mathrm{~g}$ of aluminum flakes). The peak intensities of the conductivity in these tests occur after the passage of the primary blast front with values ranging between 0.1 and 0.2 $\mathrm{S} / \mathrm{m}$. Thus the conductivity is about a factor 5 to 10 larger than in the case of the bare PETN spheres. The reflection from the tunnel entrance re-enhances the conductivity as in the tests with bare charges, but for the SDF charges the peak after the passage of the primary blast wave is the dominant one.

Though essential parameters of the measured records like the timing with respect to the arrival to shock fronts show a fair reproducibility, the scatter of the data appears to be considerable. However, in view of the results we obtained with other techniques we tried the results have to be called encouraging. 


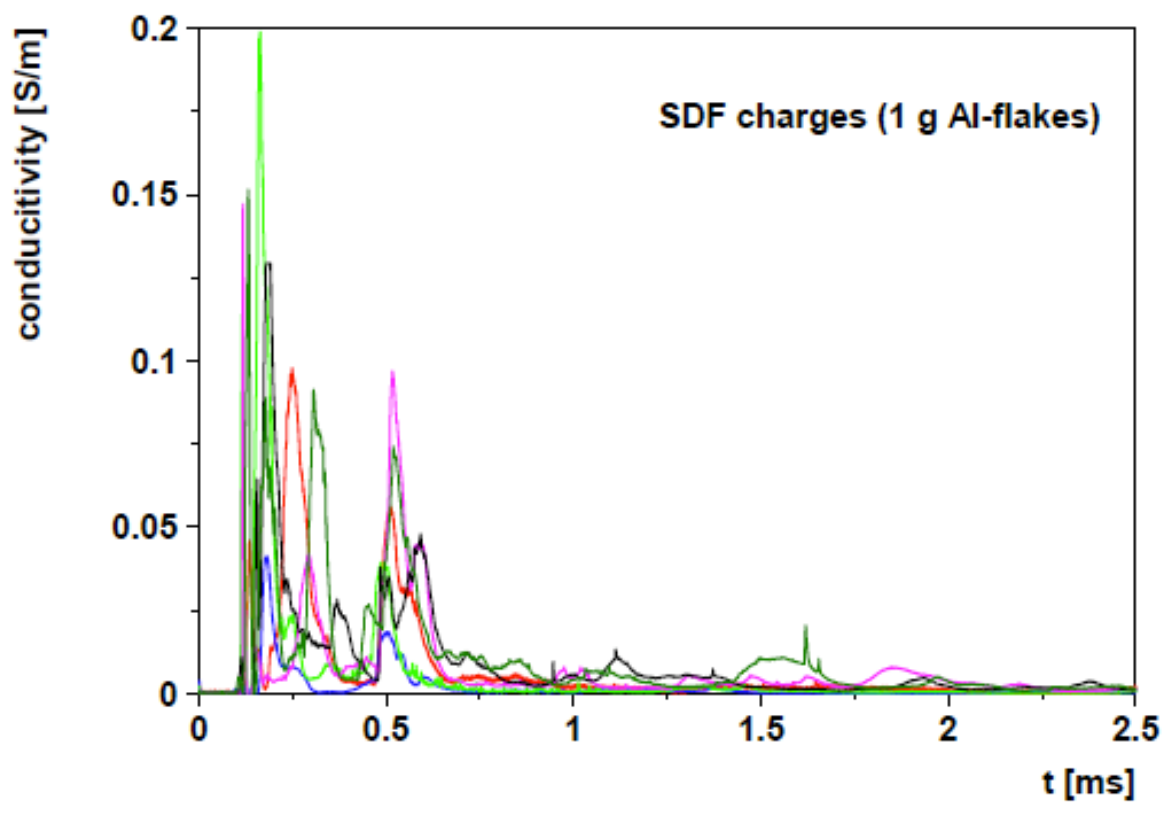

Figure 6. Time history of the electro-conductivity at $\mathrm{x}=356.7 \mathrm{~mm}$ in the $3-\mathrm{m}$ tunnel model. Six tests with standard SDF charges containing a PETN booster of $0.5 \mathrm{~g}$ and a fill of aluminum flakes of $1 \mathrm{~g}$. Measured with the wall-mounted sensor.

The basic reason for the design of this first version of a conductivity probe was to keep the gage non-intrusive to the flow-field. However, the design with electrodes flushmounted to the wall limits the spatial resolution of the probe. Since the conductivity might be distributed fairly in-homogeneously over the whole tunnel diameter, we decided to design a second probe, which provides a more localized measure, even if this probe is intrusive to the flow-field.

The basic ideas are the same as for the wall-mounted sensor. Two $8 \mathrm{~mm}$ wide stripes of copper are installed into an insulating holder. The holder has an $8 \mathrm{~mm}$ deep notch, where the cooper stripes are separated by a 4-mm wide air gap. Figure 7 shows a sketch and a photograph of this probe design. The holder can be oriented to the main flow direction and the distance of the sensing probe tip to the tunnel wall can be adjusted. This design is somewhat closer to the original idea of an ideal capacitor with a more homogeneous electrical field, even though we will still have some stray field outside of the gap between the electrodes (for a rough idea see Figure 8).

Figure 9 shows the characteristic of the point probe that we used in the experiments under report. The relation between the conductivity $\sigma$ and the voltage drop $U_{2}$ is strongly non-linear, but well suited to diagnose a conductivity range from $0.5 \cdot 10-3$ $\mathrm{S} / \mathrm{m}$ to $0.2 \mathrm{~S} / \mathrm{m}$. 

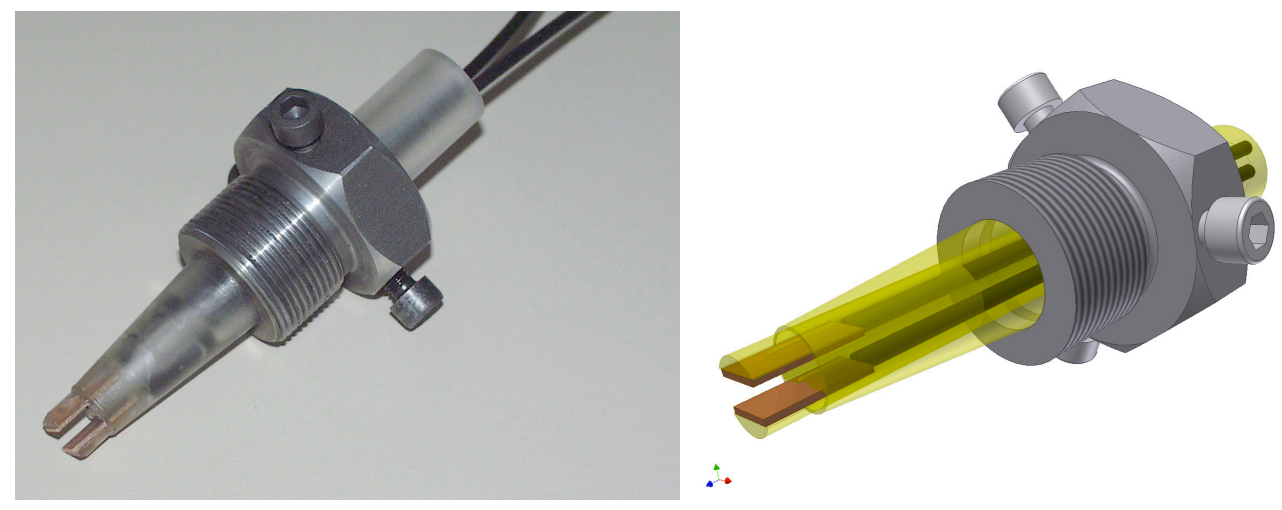

Figure 7. Photograph and schematic sketch of the point probe conductivity sensor.

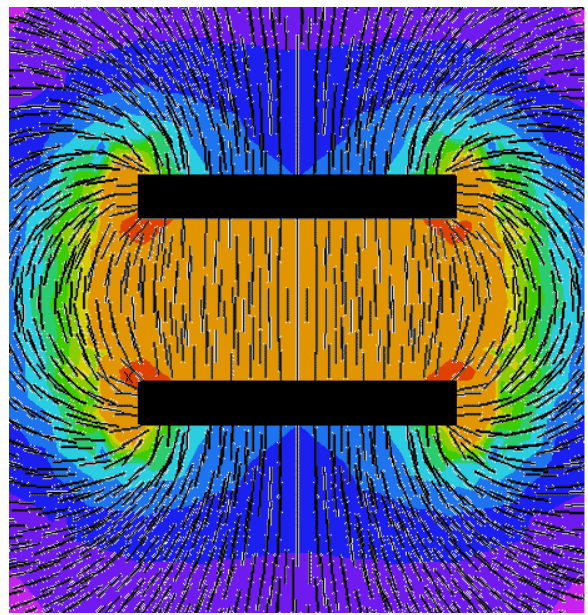

Figure 8. Electrical field of a capacitor, for which the distance between the electrodes is about half the width of the electrodes. Two-dimensional electro-static simulation.

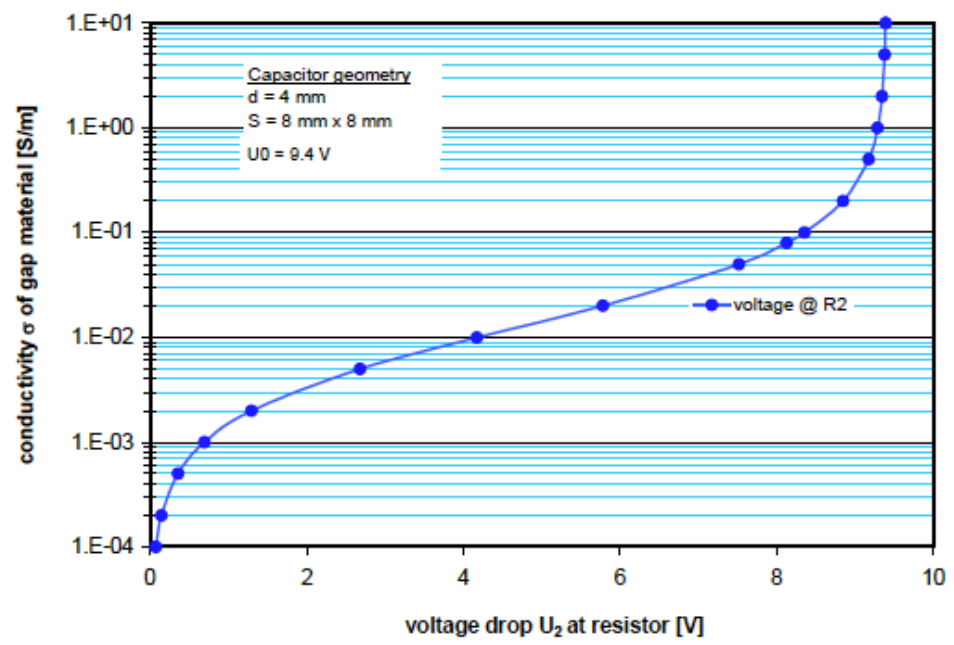

Figure 9. Characteristic curve for the conductivity point probe used in the experiments under report, relating the measured voltage $U_{2}$ to the conductivity $\sigma$. For conductivity values $\sim 1 \mathrm{~S} / \mathrm{m}$ the voltage drop is essentially equivalent to the supply voltage of $9.4 \mathrm{~V}$. 
A series of experiments with the conductivity point probe have been performed in the small-scale model of a closed tunnel section. The cross-section of the model is a square of $8 \mathrm{~cm} \times 8 \mathrm{~cm}$, the length of the closed segment is $300 \mathrm{~cm}$. A photograph of the model is shown in Figure 1. In all experiments the charges were located near to one end of the tunnel segment at $x=214 \mathrm{~mm}$. The conductivity probe was inserted into the tunnel through boreholes either in the side-wall or the roof. Various tests for different positions of the conductivity probe have been performed. Additional information was gained by the installation of piezo-electric pressure gages and photo-diodes.

We started the test series with a few initial experiments on bare spherical $0.5-\mathrm{g}$ PETN charges. In these tests the sensor was located at $x=356.7 \mathrm{~mm}$ or about $143 \mathrm{~mm}$ down from the charge. Subsequently we performed a more extensive test series on SDF charges of $1 \mathrm{~g}$ flake aluminum surrounding the $0.5 \mathrm{~g}$ PETN booster. The locations of the various gages are listed in Table 1 .

Table 1. Gage locations for the test series on SDF[1g Al flakes] charges.

\begin{tabular}{|l|c|c|c|c|r|r|r|r|r|}
\hline Test PLASMA & $66-68$ & $70-72$ & $73-76$ & $77-79$ & $80-82$ & $83-85$ & $86-89$ & $90-91$ & $92-93$ \\
\hline & {$[\mathrm{mm}]$} & {$[\mathrm{mm}]$} & {$[\mathrm{mm}]$} & {$[\mathrm{mm}]$} & {$[\mathrm{mm}]$} & {$[\mathrm{mm}]$} & {$[\mathrm{mm}]$} & {$[\mathrm{mm}]$} & {$[\mathrm{mm}]$} \\
\hline Charge & 214.0 & 214.0 & 214.0 & 214.0 & 214.0 & 214.0 & 214.0 & 214.0 & 214.0 \\
Conductivity & 356.7 & 499.4 & 642.1 & 784.8 & 1022 & 1236.0 & 1450.0 & 1664.0 & 1878.0 \\
Pressure1 & 356.7 & 356.7 & 499.4 & 784.8 & 927.5 & 1212.9 & 1355.6 & 1641 & 1783.7 \\
Pressure2 & & 642.1 & 784.8 & & 1070.2 & 1355.6 & 1498.3 & 1783.7 & 1926.4 \\
Photo1 & 280.0 & 380.0 & 594.0 & 594.0 & 808.0 & 1022.0 & 1236.0 & 1450.0 & 1664.0 \\
Photo2 & 380.0 & 594.0 & 808.0 & 808.0 & 1236.0 & 1450.0 & 1664.0 & 1878.0 & 2097.0 \\
\hline
\end{tabular}

The results for three tests with bare spherical PETN charges are shown in Figure 10. The data are not transformed to conductivity values, but given in terms of the voltage drop at the resistor $\mathrm{R}_{2}$.

An initial conductive front arrives about $80 \mu$ s after the primary blast wave has passed the probe location. (The black line in Figure 10 marks the arrival of the front, which was monitored with a pressure gage installed directly opposite the conductivity probe.) The peak voltage $\mathrm{U} 2$ ranges from 1 to $1.5 \mathrm{~V}$ indicating conductivity values in the range of $1.5 \cdot 10-3$ to $2.4 \cdot 10-3 \mathrm{~S} / \mathrm{m}$. 


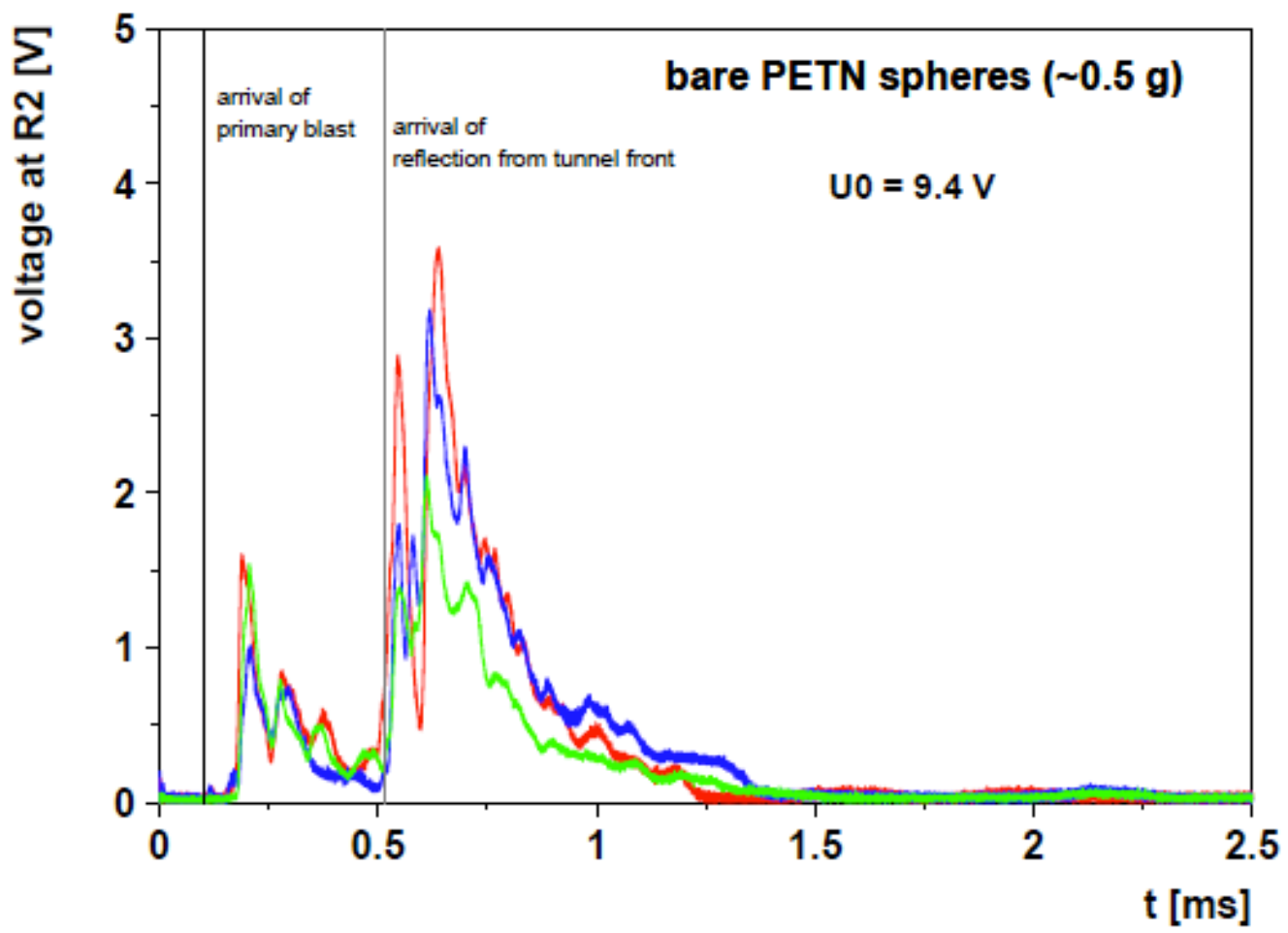

Figure 10. Time history of the voltage drop at the $5 \mathrm{k} \Omega$-resistor for three tests with bare spherical PETN charges in the tunnel model. Charge at $\mathrm{x}=214 \mathrm{~mm}$, point probe conductivity sensor at $\mathrm{x}=356.7 \mathrm{~mm}$.

Since the charges were located in some distance from the plate that closes the left side of the tunnel, a blast wave also propagates towards this end and is reflected there. The reflected wave reaches the location of the conductivity probe at about $0.5 \mathrm{~ms}$ (marked by dark gray line in Figure 10). A pronounced increase of the electroconductivity accompanies its arrival. This enhancement yields peak values of about $3.7 \mathrm{~V}$ corresponding to conductivity values of about $8 \cdot 10-3 \mathrm{~S} / \mathrm{m}$.

Figure 11 shows corresponding results for three tests with aluminum-filled SDF charges (tests 66-68). The conductivity behind the primary blast front is very strong and the delay between the blast front and the start of the conductivity signal in two cases is significantly shorter than in the case of the bare PETN charges. It ranges from a few microseconds to $40 \mu$ s. The measured voltages are around 8.8 to $8.9 \mathrm{~V}$. This indicates conductivity values in the order of $0.2 \mathrm{~S} / \mathrm{m}$. However, with voltages that close to the nominal voltage $\mathrm{U} 0$ of $9.4 \mathrm{~V}$ from the battery supply the slope of the probe characteristic becomes very steep and momentary conductivity values in excess of $0.2 \mathrm{~S} / \mathrm{m}$ are possible.

Similar to the case of the bare PETN charges the conductivity decreases after the initial peak to be reinforced by the arrival of the blast reflection from the closed tunnel front. However, for bare PETN the conductivity has decreased to approximately zero after $1.5 \mathrm{~ms}$, while the decrease is slower for the aluminum-filled SDF. In the latter case we still find some conductivity after 4 to $5 \mathrm{~ms}$. 
As can be seen from Table 1, we moved the location of the conductivity probe further down the tunnel. Figure 10-12 shows the result for three tests with the probe located at $\mathrm{x}=748.8 \mathrm{~mm}$ (tests $77-79$ ), about $7 \mathrm{x} / \mathrm{D}$ down from the charge. At this location the delay between the primary blast front and the conductive front has increased to about $510 \mu \mathrm{s}$. Nevertheless, the measured peak voltages are still on the order of $8.7 \mathrm{~V}$ indicating conductivity values around $0.16 \mathrm{~S} / \mathrm{m}$. Though the conductivity decreases quasi-exponentially with time, the arrival of blast wave reflections enhances it repeatedly, as can be seen in Figure 13. Due to the non-linearity of the probe characteristic one might overrate the importance of this reinforcement in a plot of the measured voltage: the secondary peak at about $9 \mathrm{~ms}$ corresponds to a conductivity of around $0.005 \mathrm{~S} / \mathrm{m}$ or about $3 \%$ of the conductivity observed in the first peak.

Conductivity can be observed even further down the tunnel. The last probe location with measurable conductivity was found at $\mathrm{x}=1664 \mathrm{~mm}$. The results from two tests are shown in Figure 14. With the probe located at $1878 \mathrm{~mm}$ no conductivity was observed. At $\mathrm{x}=1664 \mathrm{~mm}$ the initial probe voltage has dropped to about $3 \mathrm{~V}$, the conductivity to values around $0.006 \mathrm{~S} / \mathrm{m}$. Nevertheless, the reflection from the far tunnel end again reinforces the conductivity to values of $0.035 \mathrm{~S} / \mathrm{m}$ (about a factor of 6).

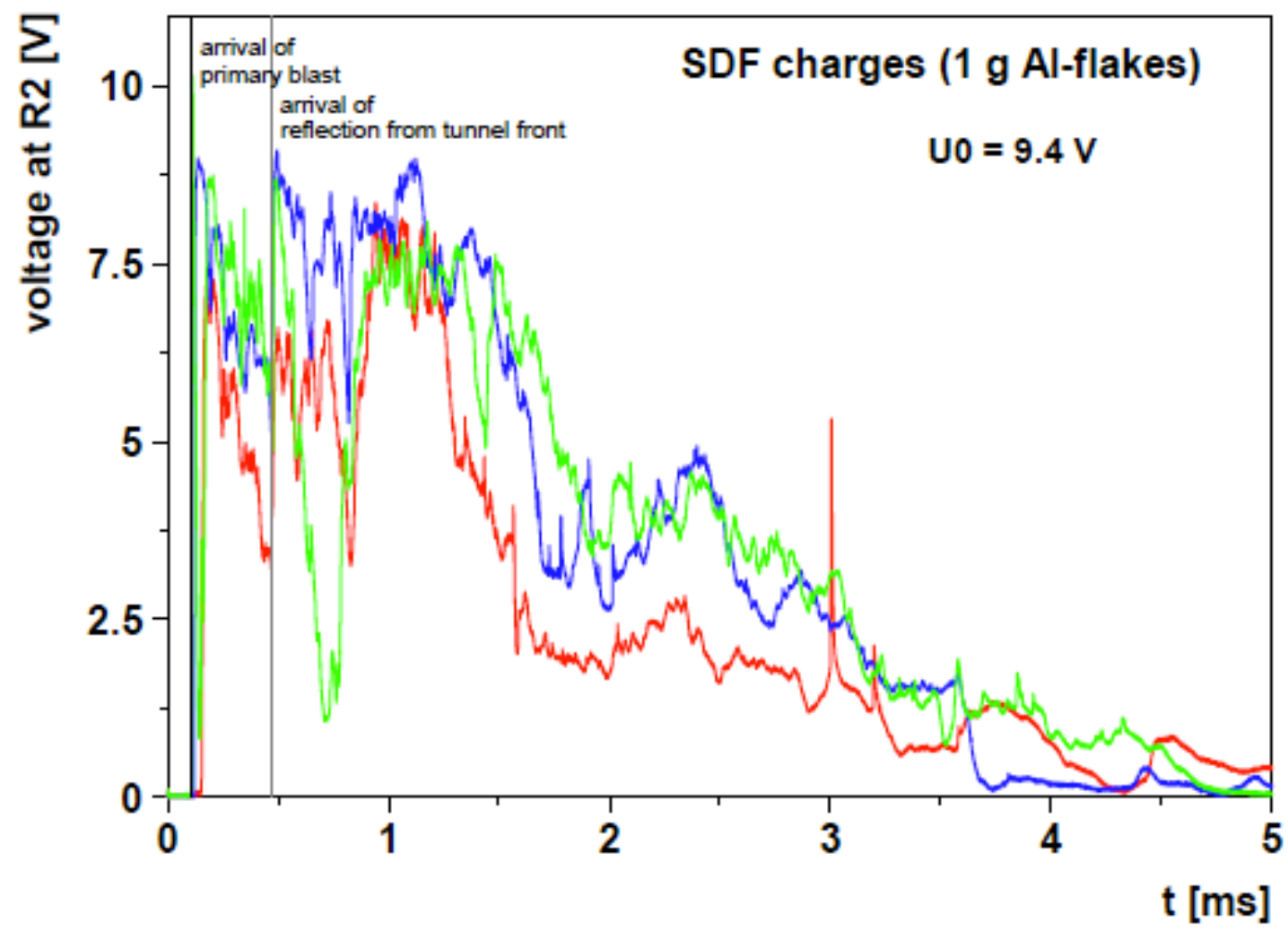

Figure 11. Time history of the voltage drop at the $5 \mathrm{k} \Omega$-resistor for three tests with standard SDF charges filled with $1 \mathrm{~g}$ Al-flakes in the tunnel model. Charge at $\mathrm{x}=214$ $\mathrm{mm}$, point probe conductivity sensor at $\mathrm{x}=356.7 \mathrm{~mm}$. 


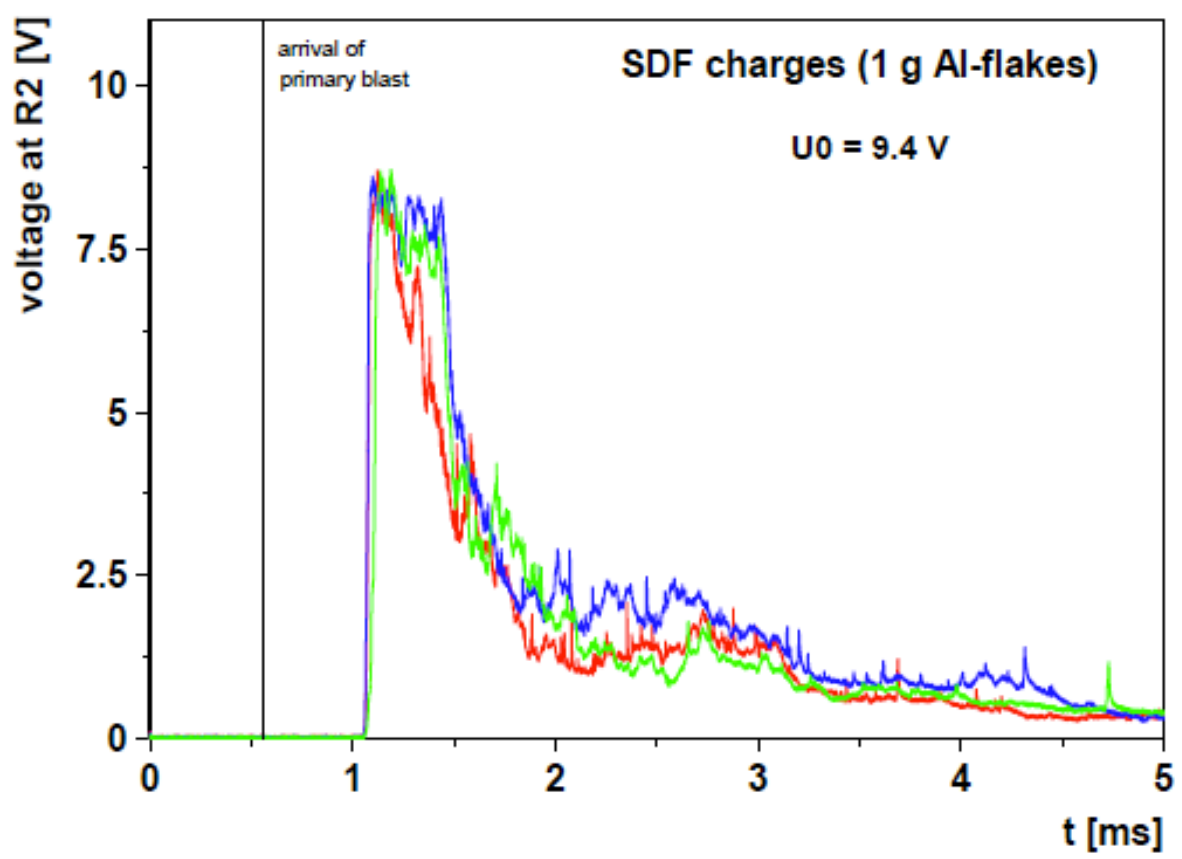

Figure 12. Time history of the voltage drop at the $5 \mathrm{k} \Omega$-resistor for three tests with standard SDF charges filled with $1 \mathrm{~g}$ Al-flakes in the tunnel model. Charge at $\mathrm{x}=214$ $\mathrm{mm}$, point probe conductivity sensor at $\mathrm{x}=784.8 \mathrm{~mm}$.

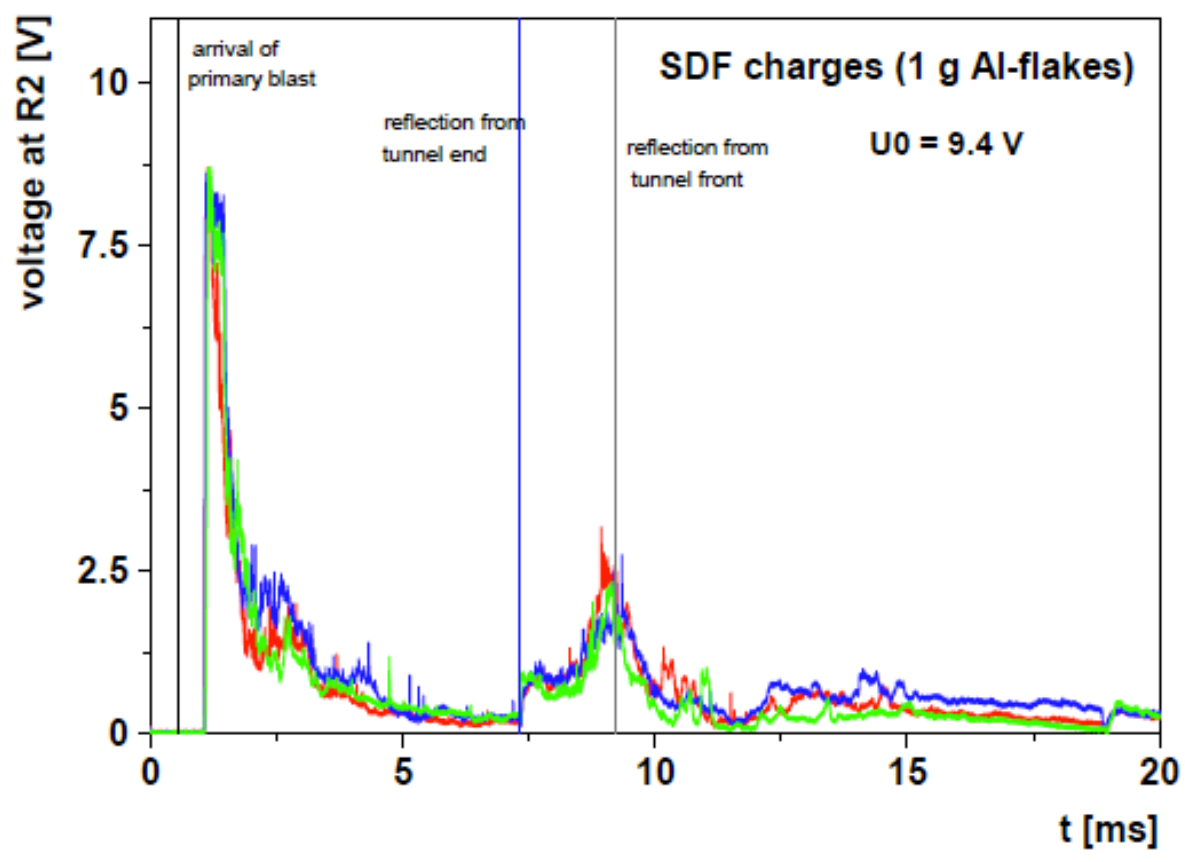

Figure 13. Time history of the voltage drop at the $5 \mathrm{k} \Omega$-resistor for three tests with standard SDF charges filled with $1 \mathrm{~g}$ Al-flakes in the tunnel model. Charge at $\mathrm{x}=214$ $\mathrm{mm}$, point probe conductivity sensor at $\mathrm{x}=784.8 \mathrm{~mm}$. 


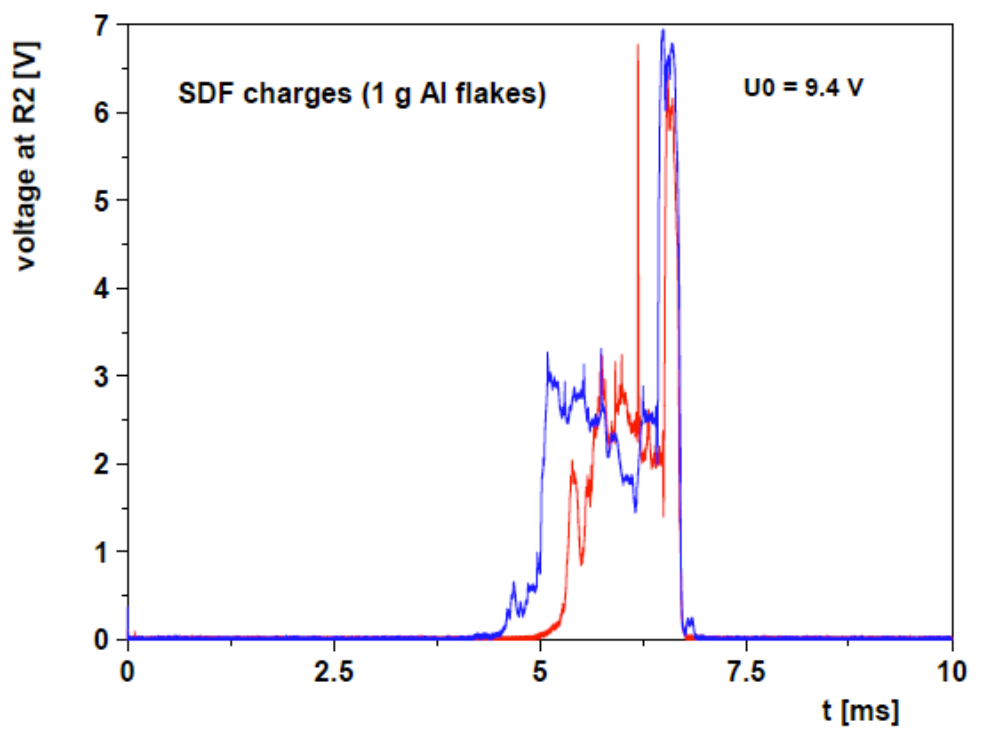

Figure 14. Time history of the voltage drop at the $5 \mathrm{k} \Omega$-resistor for two tests with standard SDF charges filled with $1 \mathrm{~g}$ Al-flakes in the tunnel model. Charge at $\mathrm{x}=214$ $\mathrm{mm}$, point probe conductivity sensor at $\mathrm{x}=1664 \mathrm{~mm}$.

The data from the conductivity probe and the pressure gages have been utilized to construct a wave diagram for the conductive region evolving from the detonation of an aluminum-filled SDF charge detonated at $x=214 \mathrm{~mm}$. From the pressure records we obtained the time-of-arrival for the primary blast front and for the blast front reflected at the far end of the tunnel. Similarly we analyzed the signals of the conductivity probe for the time-of-arrival of the conductive material. Plotting these time-of-arrival values against the gage locations yields the three black lines in Figure 15. The time histories of the conductivity probe voltage at different locations are plotted as vertical colored lines. The hue of a line segment encodes the value of the voltage according to a logarithmic scale from $0.01 \mathrm{~V}$ to $10 \mathrm{~V}$.

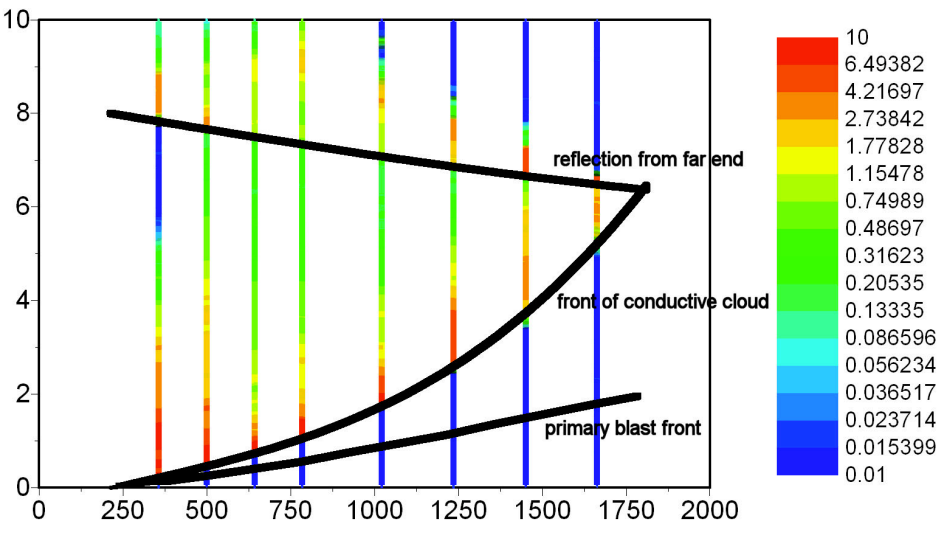

Figure 15. Initial step for the construction of a wave diagram for the conductive region evolving from the detonation of an aluminum-filled SDF charge. X-axis: location in the tunnel in $\mathrm{mm}, \mathrm{y}$-axis: time in $\mathrm{ms}$, color code: conductivity probe signal in $\mathrm{V}$. 
In a second step the regions between the colored lines were filled using an approximate interpolation. The resultant wave diagram is shown in Figure 16. Obviously the conductive cloud initially follows the primary blast wave at a high velocity, but slows down considerably on its way down the tunnel. In the range from $x=214 \mathrm{~mm}$ to about $\mathrm{x}$ $=1000 \mathrm{~mm}$ the conductive cloud is defined by a sharp front, further down the tunnel we observe a delay between the onset of conductivity and its maximum. At a distance of $\mathrm{x}=$ $1800 \mathrm{~mm}$ and a time of about $6.5 \mathrm{~ms}$ the blast reflection from the far tunnel end impinges onto the conductive cloud. In subsequence the cloud is pushed backwards towards the tunnel front. It is also compressed and reheated, which seems to be the reason for the reinforcement of the conductivity the goes along with the arrival of the reflected shock.

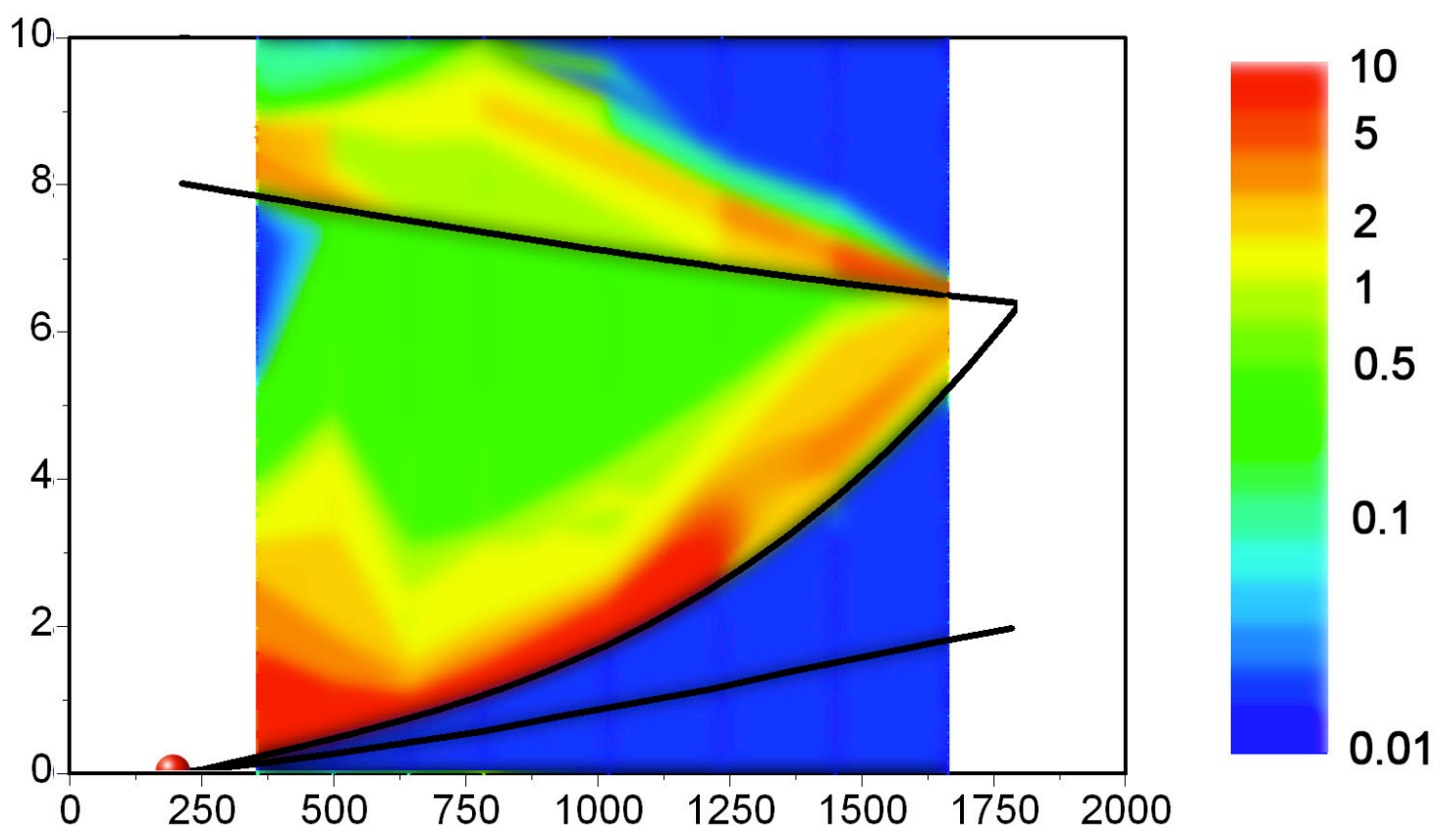

Figure 16. Approximate wave diagram for the conductive region evolving from the detonation of an aluminum-filled SDF charge.

We have observed a similar phenomenology for the luminosity from the combusting fuel in previous experiments. Thus we constructed a comparable wave diagram from the photo-diode records from the current test series. The observed photovoltages ranged from 0 to $0.2 \mathrm{~V}$. These were multiplied by a factor of 50 so that the same color-coding could be applied to the photo-diode records. The resultant wave diagram is shown in Figure 17. The general evolution of the luminous region is very similar to that of the conductive region. One noteworthy difference is that for locations beyond $\mathrm{x}=1000$ $\mathrm{mm}$ the region of maximum luminosity does not coincide with the region of maximum conductivity. This is exemplified in Figure 10-18, which shows the time history of the conductivity at $\mathrm{x}=1236 \mathrm{~mm}$ in comparison to the history of the photodiode read-out. The conductivity signal starts at about $2.5 \mathrm{~ms}$ with a steep rise to the maximum value. The photo signal, which sets on at approximately the same time, increases more slowly to its maximum, which is attained at around $3.3 \mathrm{~ms}$. 


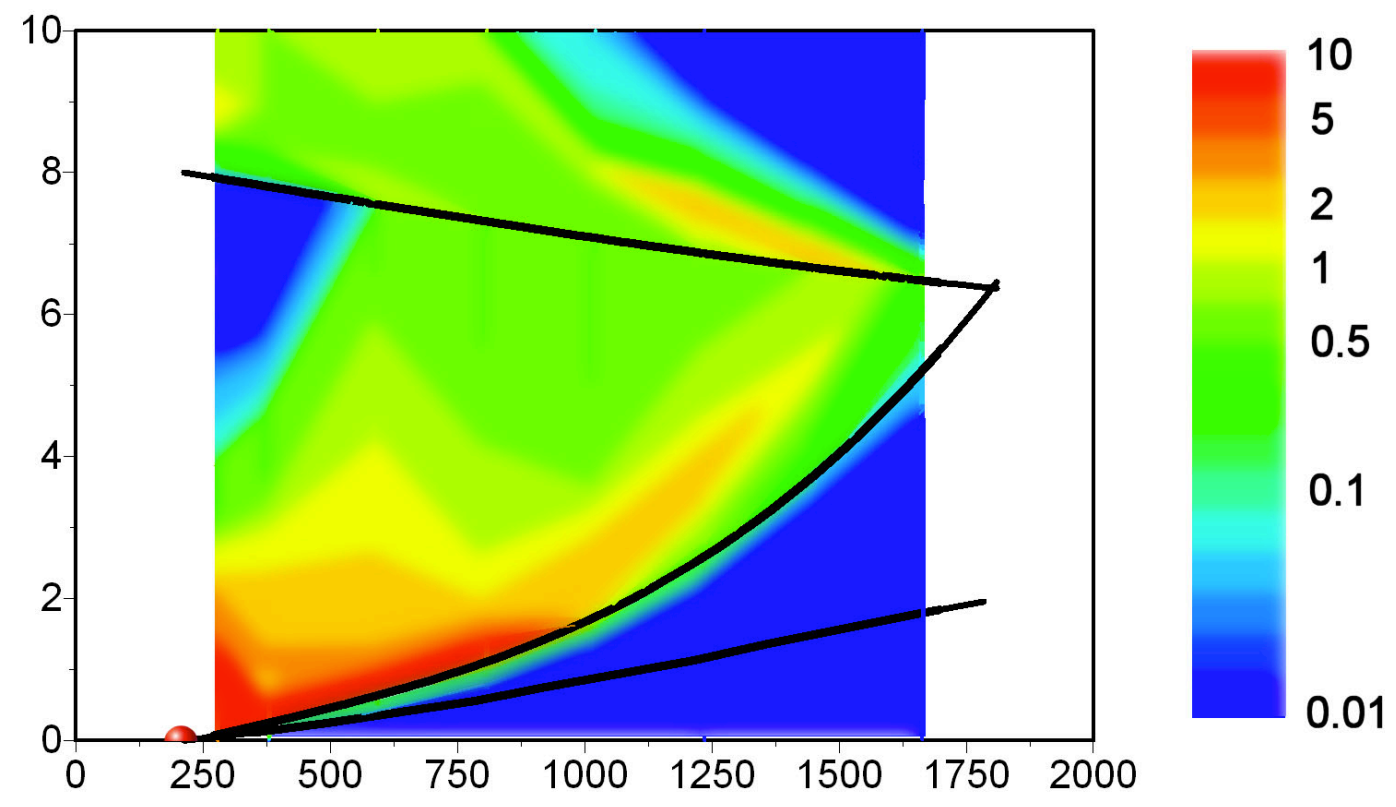

Figure 17. Approximate wave diagram for the luminous region evolving from the detonation of an aluminum-filled SDF charge.

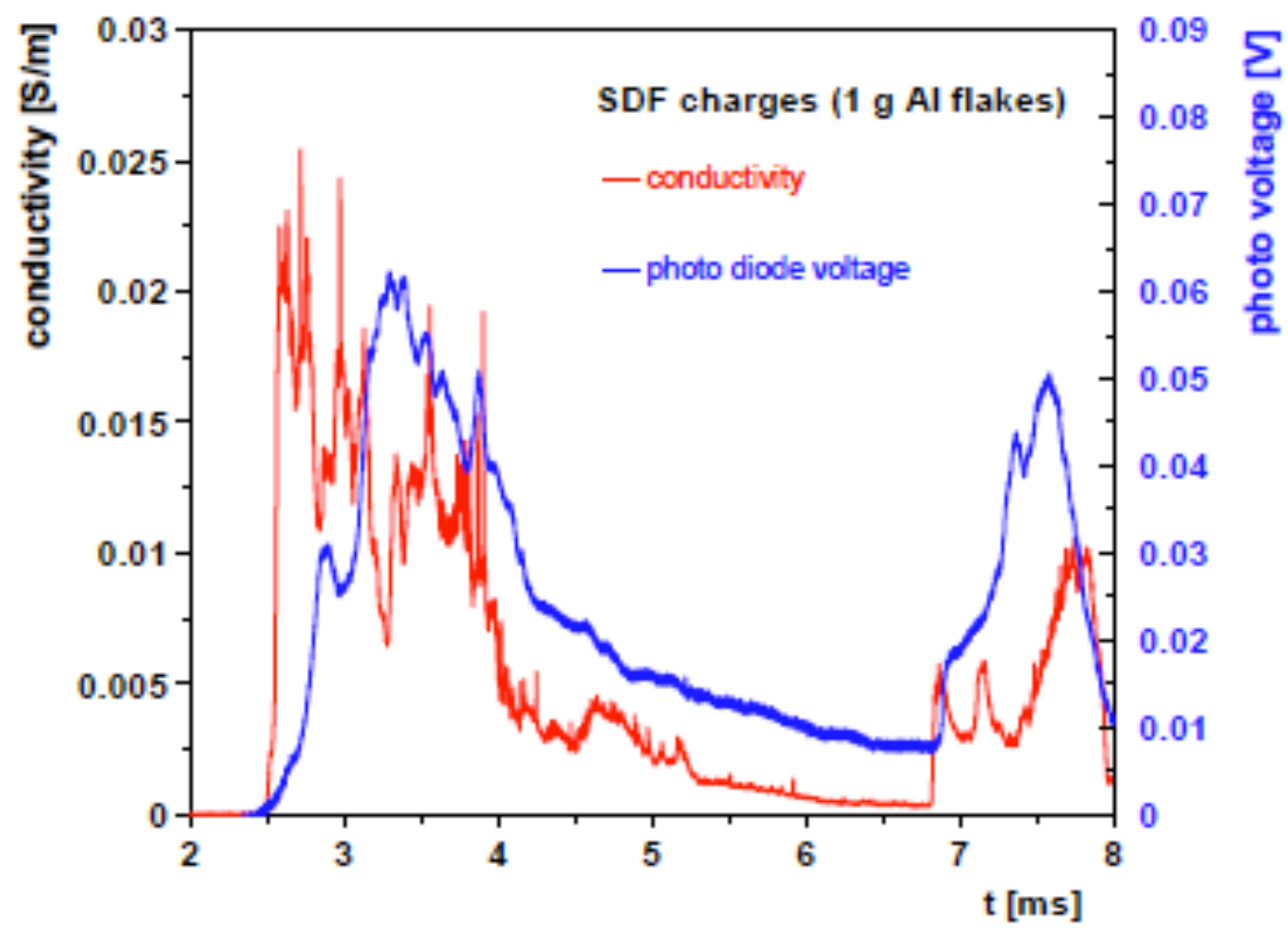

Figure 18. Comparison of the time history of the conductivity (red) and the photo-diode voltage (blue) at $\mathrm{x}=1236 \mathrm{~mm}$. 


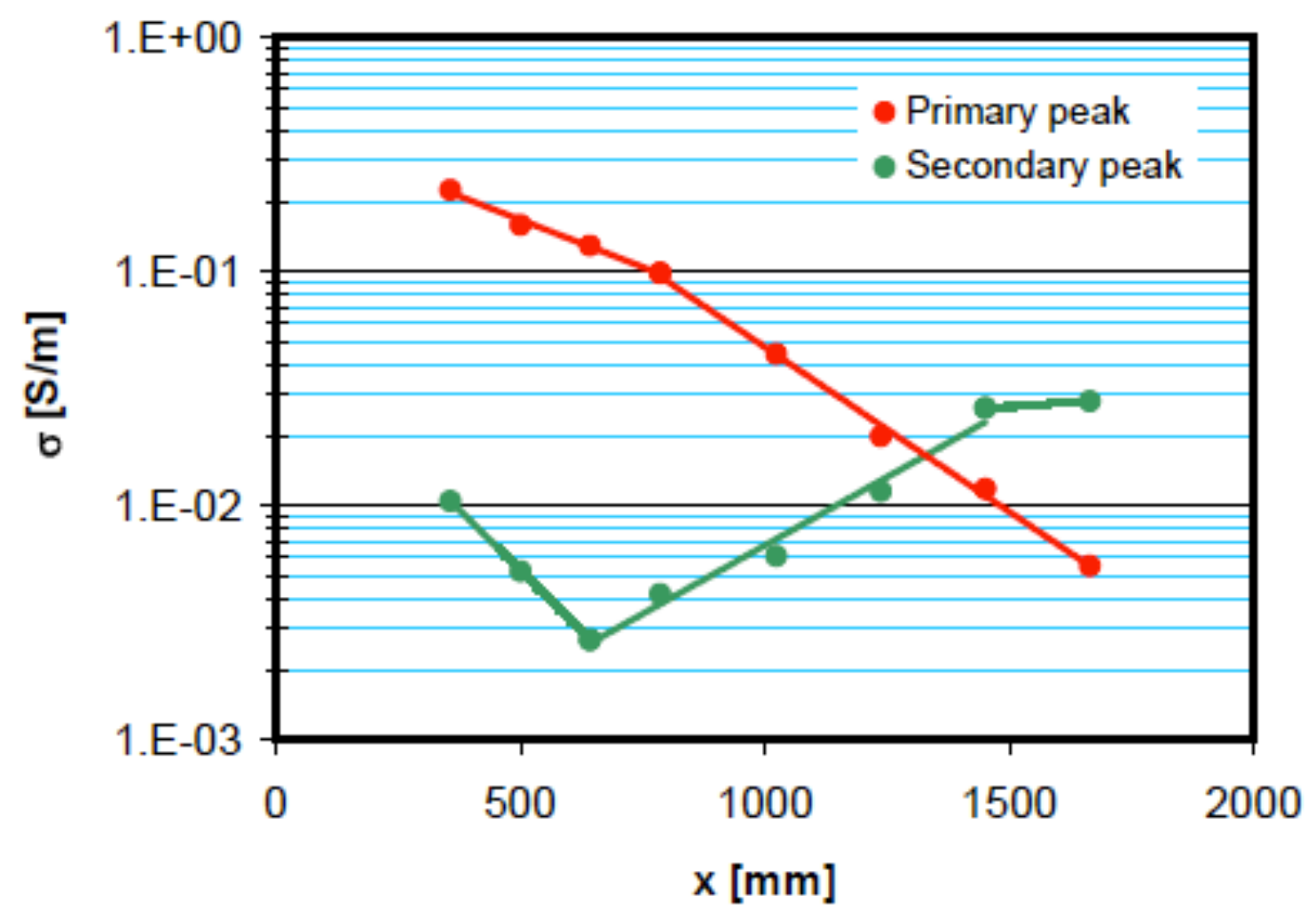

Figure 19. Evolution of the conductivity along the tunnel. The term secondary peak denotes the maximum conductivity after reinforcement by the wave reflection from the far tunnel end.

Since the previous figures (except Figure 18) mainly presented the measured voltage from the conductivity probe instead of the conductivity values, Figure 19 shows how the maximum conductivity values evolve along the tunnel length. Essentially they decay exponentially with a characteristic decay length of $525 \mathrm{~mm}(6.6 \mathrm{D})$ in the range to $\mathrm{x}=800 \mathrm{~mm}$ and a characteristic decay length of $312 \mathrm{~mm}(3.9 \mathrm{D})$ in the range from $\mathrm{x}=$ $800 \mathrm{~mm}$ to $1600 \mathrm{~mm}$.

Figure 19 also includes values for the secondary peak due to reinforcement by the reflected blast wave from the far tunnel end. In the range around $x=1500 \mathrm{~mm}$ (i.e., close to the tip of the conductive region) the blast reflection not only causes a reinforcement, but a considerable increase above the values for the primary peak. 


\section{References}

[1] Neuwald, P.; Reichenbach, H.; Kuhl, A. L.; Combustion of Shock-Dispersed Fuels in a Chamber, 11th Int. Symposium on Interaction of the Effects of Munitions with Structures, Mannheim, Germany, May 5 -9, 2003.

[2] Neuwald, P.; Reichenbach, H.; Kuhl, A. L.; Shock-Dispersed Fuel Charges Combustion in Chambers and Tunnels I, 34th Int. Conf. ICT, Energetic Materials, Karlsruhe, Germany, June 24 -27, 2003, ISSN 0722-4087.

[3] Neuwald, P.; Reichenbach, H.; Kuhl, A. L.; Shock-Dispersed-Fuel Charges Combustion in Chambers and Tunnels II, 19th Int. Colloquium on the Dynamics of Explosions and Reactive Systems, Hakone, Japan, July 27 - August 1, 2003.

[4] Neuwald, P.; Reichenbach, H.; Blast in a Tunnel Segment - Pressure Loads at the End Wall, Proc. 18th Conference on Military Aspects of Blast and Shock, Bad Reichenhall, Germany, October 2004.

[5] Kuhl, A. L.; Neuwald, P.; Reichenbach, H.; Combustion of a Shock-Dispersed FlakeAluminum Charge in a Chamber, Proc. 18th Conference on Military Aspects of Blast and Shock, Bad Reichenhall, Germany, October 2004. 